This work forms part of a lightning investigation which is being conducted by a Committee of the South African Institute of Electrical Engineers, whom we thank for permission to publish this letter.

University of Cape Town.

$$
\text { B. F. J. SCHONLAND. }
$$

Victoria Falls and Transvaal

$$
\text { H. Collens. }
$$

Power Company, Johannesburg.

C. V. Boys, NatURE, 118, 749, Nov. 20, 1926 ; 122, 310, Sept. 1, 1928. E. C. Halliday, Phil. Mag., 98, 409 ; 1983.

\section{Habit and Structure in Starfishes}

IT is, in general, extremely difficult to determine the exact purpose and function of the organs of marine invertebrate animals. Observation of such animals under purely natural conditions is often impossible: when they are captured and examined in tanks they are generally half-asphyxiated with toxins, and those familiar with aquaria know that it is far more difficult to acclimatise invertebrates to life in captivity than it is to acclimatise vertebrates such as fish.

Sometimes, however, by a happy concatenation of circumstances, one obtains a flash of insight into the working of the parts of an invertebrate such as months of carefully prepared experiments have failed to yield.

In the summer of 1905 , when I was studying the embryology of the brittle star Ophiothrix at Plymouth, I had a consignment of these animals, which had been captured near the Eddystone, brought into the biological station. They were placed in a jar containing 'outside water', that is, sea-water dipped up outside Plymouth Sound. On the upper surface of the dises of nearly all brittle-stars there is a circle of ten plates shaped rather like the petals of a flower. There never had been any explanation of these plates adduced other than to attribute them to the mysterious forces of ornament and symmetry. But on the occasion of which I speak, to my amazement I saw the dises of these brittle-stars rising and falling like bellows. Then I remembered having seen in my sections of Amphiura, muscles connecting the upper and lower surfaces of the disc near the edge. The genital bursa; a pocket of the under side of the disc, which has a respiratory function, is attached by fibrous cords to the lower surface of the petallike plate; this plate is hinged to a plate, termed the genital plate, placed on the lower surface of the brittle-star, running along the opening of the bursa. The result of this arrangement is that the petal-like plate and the genital plate act conjointly as a pair of bellows alternately expanding and compressing the genital bursa and thus forcing sea-water in and out of it. Under ordinary conditions, the influx of water is controlled by tho motion of the cilia lining the bursa, but when the demand for oxygen becomes acute then this 'forced breathing' comes into play. That I was lucky enough to witness it I attribute to the circumstances : (1) that the supply of oxygen in the jar was being diminished by the rays of the evening sun shining through it; and (2) the sea-water was very pure and that the animals were therefore in a healthy condition.

This summer another lucky chance enabled me to understend the meaning of the differences of structure subsisting between different families of ordinary starfish (Asteriidæ). Two very distinct types of these starfish are common around our coast. One, typified by the ordinary starfish Asterias, includes denizens of clean clear sea-water with a relatively firm bottom over which they crawl. These starfish have clear, transparent, finger-like gills projecting from both upper and under surfaces. Their organs of locomotion (tube feet) terminate in suckers and by means of these the starfish can climb vertical walls of rock. The other type, represented by Astropecten, have gills only on their upper surface, their tube feet are pointed and they are consequently unable to climb; they are found on soft, muddy sand over the surface of which they run. They eagerly consume bits of somewhat stale fish, and in Plymouth they can be seen to swallow these. After the meal is completed, they proceed to bury themselves in the and. The body is completely covered except for the centre part of the back which is raised into a cone projecting into the water, and on this cone nearly all the gills are concentrated. In the deep-sea family Porcellanasteridæ this cone has become a permanent organ: it is cylindrical and long and was interpreted by Perrier as a remnant of the stem which, he thought, the supposititious Crinoid ancestors of the starfish must have possessed! Thus the temporary elevation of the back in one family has become a permanent structure in an allied family.

This summer I had sent me from Plymouth a consignment of the common starfish Asterias. I desired to repeat the experiment once before successfully carried out in my laboratory, of rearing the eggs of this form through the larval stage to maturity. These starfish are delicate organisms, and if sent packed in damp seaweed, usually fail to survive the passage from Plymouth to London. Accordingly they were sent to me in a large tub half full of seawater hermetically sealed. All arrived in London living but not very active. To revive them they were placed in one of our shallow laboratory tanks and an air-circulation was introduced into the water. The air pipe did not reach the bottom of the tankin fact, it projected only a few inches below the surface. To my amazement $I$ found that all the starfish had elevated the centre of the back-in the manner just described for Astropecten - so as to bring this part of the body into contact with the airbubbles which were being shot into the water. Under natural conditions, one would think that this elevation of the back must rarely be called for : but evidently the power to produce it is present in all starfish, and in Astropecten and its allies, with the assumption of the burying habit, this power has been intensified and specialised.

Truly structure is only frozen habit.

\section{E. W. MAcBride.}

Imperial College of Science and Technology, London, S.W.7. Aug. 18.

\section{Effect of Yeast Extract on the Growth of Plants}

CULTURE experiments which we have carried out with peas have shown that yeast extract-prepared by heating yeast in water-stimulates to a remarkable extent the development of blossoms. In these experiments, the plants were grown either in sterile culture fluids ( $p \mathbf{H} 6.5$ ) or in quartz sand, watered with Hiltner's nutriment solution. Nitrogen was 